\title{
EL TEMA DE LA
}

CIUDAD EN

ALGUNOS

PENSADORES

CONTEMPORÁNEOS

Jaime Ruiz de Santiago*

\section{Se trata de investigar las principales}

notas que caracterizan a la ciudad de nuestros días - fundamentalmente en el mundo occidental- y cuáles son las tendencias que apuntan al futuro. Para ello, he seleccionado algunos autores contemporáneos cuyas posiciones poseen destacada importancia para este tema.

\section{Zygmunt Bauman}

El primero de ellos es Zygmunt Bauman, por la relevancia de sus posiciones acerca del "mundo líquido" en el cual vivimos, al igual que por sus análisis referentes a los movimientos migratorios que lo caracterizan. Todo ello condiciona lo que significa "vivir en la ciudad". Este pensador ha presentado los aspectos más propios de lo primero, sobre todo en su obra Tiempos líquidos. ${ }^{1}$ Con relación a las migraciones, me permito sobre todo referirme a mi estudio relativo al tema. ${ }^{2}$ Lo concerniente a las consecuencias que de estas tesis se siguen aparecen en la obra Confianza y temor en la ciudad. Vivir con extranjeros, ${ }^{3}$ al igual que en una de sus últimas obras, Extraños llamando a la puerta. ${ }^{4}$

* Departamento Académico de Estudios Generales, ITAM.

${ }^{1}$ Zygmunt Bauman, Tiempos líquidos (Barcelona: Tusquets, 2007), 7-11.

${ }^{2}$ Jaime Ruiz de Santiago, "Sentido e importancia de las migraciones en un mundo líquido", Estudios 125 (2018): 73-102.

${ }^{3}$ Barcelona: Arcadia, 2006.

${ }^{4}$ Barcelona: Paidós, 2016. 
Los tiempos líquidos en los que vivimos se caracterizan ante todo por el paso de la modernidad sólida a la líquida, es decir, de tiempos en que se conocían estructuras y formas sociales firmes y aparentemente estables, a otros en los cuales esas características se diluyen y se "licúan". Son los tiempos anunciados por el pensador griego en los que "todo cambia" (panta rei).

El segundo aspecto se refiere a la separación cada vez más radical entre poder y política, que afecta fundamentalmente al Estado-nación que hasta el momento ha prevalecido, pero al cual esa escisión pone cada día en mayor riesgo: el Estado pierde control y capacidad para establecer la dirección y las acciones para realizar los objetivos planteados y estos se desplazan a actores globales que progresivamente quitan importancia a las instituciones políticas existentes.

El tercer aspecto está significado por la gradual reducción y supresión de los seguros que habían sido puestos por el Estado para garantizar la satisfacción de necesidades individuales, tales como los riesgos de la salud, la educación, la construcción y uso de carreteras, los transportes públicos, servicios tales como la energía eléctrica o el agua, la recolección de basura, etc. Con ello se pierde el sentido de lo que se conoce con el nombre de "comunidad" o de "solidaridad".

En cuarto lugar, se acorta el pensamiento y los planes de largo plazo para reducir los proyectos y episodios de la vida a una corta duración, de modo que las realizaciones alcanzadas son objeto de revisión y cambios constantes. Todo lo logrado vale "hasta nuevo aviso", que seguramente no tardará en llegar.

En quinto y último lugar los tiempos líquidos significan que las responsabilidades individuales hacen referencia no tanto a normas generales, que con frecuencia son escasas y a menudo contradictorias, sino a la capacidad para ser flexible y descubrir caminos imprevistos y creativos, lo que implica la capacidad para abandonar rápidamente compromisos y lealtades adquiridas para estar abierto a las oportunidades que se presentan en un momento determinado y que seguramente serán de una corta duración.

Estos cambios tienen como tela de fondo un "paradigma económico" que se ha transformado en las últimas décadas. En efecto, lo propio de 
los siglos XVIII y XIX, durante los cuales se generó una técnica que encontró pronta aplicación en la producción de bienes de consumo, fue una economía de producción que logró hacer creer que el único progreso posible es aquel que se refleja en las industrias, en las chimeneas de las fábricas, en los grandes centros industriales, en las ciudades que se crean en torno a tales centros de producción y que hacen vivir en torno suyo a quienes se dedican a esas actividades.

Tal economía de producción fue substituida por una economía de consumo, que supo educar a sus miembros en "el arte de consumir", que les proveyó de bienes que respondían a necesidades naturales y sobre todo artificialmente creadas, que supo crear una cantidad siempre mayor de tales bienes de consumo, caracterizados no solo por su número siempre creciente, sino también por una novedad que no deja de suscitar un apetito voraz por adquirir, usar y dejar atrás lo más pronto posible. Este paradigma se ejemplifica en los grandes centros comerciales, que han substituido a las antiguas catedrales, que moldean existencias entregadas religiosamente a la búsqueda de los nuevos artículos para adquirir y usar y que, sobre todo, anuncian novedades que aparecerán en el futuro. Se logra así el consumidor-tipo, para quien la vida solo adquiere sentido por consumir: "para el consumidor cabal y maduro, actuar de esa manera es una compulsión, una obligación. Pero esta 'obligación', esa presión interiorizada, esa imposibilidad de vivir la vida de otra manera, se le revela disfrazada de ejercicio del libre albedrío". ${ }^{5}$

Con este paradigma económico, las ciudades cambian de estructura: las fábricas e industrias tienden a alejarse por su carácter contaminante y los nuevos centros de crecimiento son naturalmente los centros comerciales en torno a los cuales gira la vida de las personas. La gran tarea, que aparece como gran distracción, es la adquisición de los nuevos productos, en espera nunca satisfecha de las "últimas novedades".

Pero esta economía de consumo pronto deja su lugar a un nuevo paradigma: una economía de finanzas, en la cual la riqueza no se obtiene por la producción y el intercambio de bienes producidos, ni por la ganancia económica que arroja su consumo, sino de finanzas que hacen refe-

${ }^{5}$ Zygmunt Bauman, La globalización. Consecuencias humanas (Buenos Aires: FCE, 2010), 89-90. 
rencia a un universo global que se desarrolla en un espacio virtual y analógico. Los antiguos centros financieros abandonan los lugares que ocupaban en las antiguas ciudades y se trasladan a las afueras, a nuevos sitios que se pretenden autosuficientes y debidamente alejados de la vida común y corriente y desde donde se pretende controlar los fenómenos globales que constituyen al mundo.

Estas transformaciones han sido acompañadas de la transformación de la naturaleza y misión del Estado-nación. Este cambio fundamental, al cual se ha hecho ya una breve referencia, significa, en un primer momento, que lo que substituye a estructuras políticas medievales aparece justificado por ser una instancia que procura remediar las necesidades de las personas que lo constituyen, sobre todo en momentos en que estas corren peligro: se trata del welfare State, que se entiende por esta capacidad para apoyar a los individuos para obtener educación, conservar la salud, proveer los elementos esenciales para mantener la existencia (agua, alimentos y otros), construir carreteras y un sistema adecuado de energía eléctrica, proyectar y realizar reclusorios para aquellos que son un peligro para la existencia e integridad de las ciudadanos, etc. Pero este Estado se ha ido erosionando, entre otras causas por un sistema capitalista cada vez más voraz, al igual que por la aparición de los actores 222 globales que reducen de manera drástica el ser y quehacer del Estado. Este sacrifica su naturaleza de proveedor de remedios contra los peligros que acechan a la existencia y transfiere la misión a otros sujetos, ya sean los mismos sujetos particulares que se encuentran cada vez más reducidos a sus propios recursos y capacidades para remediar tales necesidades, ya sean los agentes globales que han asumido la realización de tareas por las que los individuos deben pagar precios cada vez más caros. "La sociedad ya no está protegida por el Estado, o por lo menos difícilmente confía en la protección que este ofrece; ahora se halla expuesta a la voracidad de fuerzas que el Estado no controla y que ya no espera ni pretende recuperar y subyugar". ${ }^{6}$ En esta nueva situación, el Estado es "administrado por los mercados, por los grupos financieros, por fuerzas supranacionales que se sustraen a todo control democrático".?

${ }^{6}$ Bauman, Tiempos líquidos, 40.

${ }^{7}$ Zygmunt Bauman y Carlo Bordoni, Estado de crisis (Barcelona: Paidós, 2016), 28. 
El Estado se ve obligado a encontrar una nueva justificación a su existencia y la encuentra rápidamente en la tarea de garantizar la seguridad de las personas que lo integran. Se crea un Estado policía en el cual se multiplican las normas que tipifican y condenan conductas delictivas y cuyo estricto cumplimiento hace sentirse seguros a los miembros que lo constituyen. Como pronto esto no parece suficiente, el Estado comienza a buscar nuevos peligros para la sociedad, peligros contra los cuales advierte y que se designan mediante un lenguaje descriptivo que hace aparecer y resaltar su naturaleza hostil y maligna. De este modo, se advierte a la opinión pública de acechanzas que la rodean con elementos cuya peligrosidad desconocía, pero que el Estado devela y presenta con caracteres obscenos.

En este escenario aparece una realidad que ha sido producida por la situación económica dominante en el Estado. Tal realidad se presenta con el capitalismo de producción, pero aumenta vertiginosamente con el de consumo y, finalmente, con el financiero, pues este último se ve reforzado por una tecnología cada vez más poderosa gracias a la cual se requiere un número siempre menor de trabajadores, así que la clase obrera pierde gradualmente protagonismo. Pero desde el principio de la modernidad se ha segregado una cantidad cada vez más importante de personas que son desechadas por el sistema, que no pueden cumplir con las exigencias de la sociedad en la que se encuentran, que constituyen la clase pobre que, lenta pero inexorablemente, se convierte en algo que se localiza todavía más abajo: se trata de verdaderos "desperdicios humanos", "descartables", "excluidos", que son sentidos "de más" y que en ninguna parte encuentran acomodo.

En un momento de la historia estos “excedentes de población” fueron dirigidos a tierras que se consideraban de nadie, espacios vacíos y listos para ser ocupados. También fueron carne de cañón para los enfrentamientos bélicos e incluso se ha intentado que sus integrantes se liquiden entre sí. Pero cada vez se constata con mayor claridad que tales excedentes no encuentran vías de escape, pues "se encuentran obstruidos los canales normales de desagüe".

Ante tales realidades, las personas con posibilidades económicas, sobre todo los ricos, procuran alejarse y, dejando el centro de las ciudades, 
se retiran a sitios que les ofrezcan seguridad, sitios a los que de ninguna manera se puede ingresar fácilmente, lugares bardeados, protegidos por sistemas de seguridad. Ahí los ricos se sienten a salvo, alejados de ese peligro que amenaza en las calles y los lugares más insospechados, el peligro del que el Estado alerta y contra el que no deja de luchar.

Los Estados advierten que es necesario protegerse contra los inmigrantes, contra los pobres, contra los peticionarios de asilo, contra quienes ingresan en otros países para resolver sus problemas económicos, contra los refugiados...

Los refugiados y los inmigrantes, que vienen de "tierras remotas", pero solicitan establecerse en la vecindad, solo sirven para conjurar el espectro de las "fuerzas globales", temidas e invisibles porque llevan a cabo su tarea sin consultar con aquellos que están destinados a sufrir las consecuencias. Después de todo, los solicitantes de asilo y los "inmigrantes económicos" son réplicas colectivas (¿un álter ego?, ¿compañeros de viaje?, ¿imágenes especulares?, ¿caricaturas?) de la nueva élite dominante del mundo globalizado, de la que muchos sospechan, y con razón, que es la verdadera villana de la obra. ${ }^{8}$

Es así como los Estados alientan una mixofobia creciente que ve 224 en los otros un peligro inminente y a quienes es preciso encerrar en lugares adecuados (prisiones, centros “de recepción”, campos de inmigrantes irregulares, campos de refugiados) o procurar que de ninguna manera lleguen. Así proceden países como Australia, Polonia o Hungría. La misma Unión Europea propuso en los tiempos del primer ministro Blair, $\mathrm{y}$ esto se ha repetido en momentos muy recientes, que en estos casos - a los que nunca se designa como personas - se pague a países lejanos para que los detengan e imposibilite su llegada a los territorios a donde quieren ir. Por ejemplo, la Unión Europea ha ofrecido a Turquía que se encargue de detener a quienes buscan penetrar en el espacio europeo. Otros países, como Libia, Túnez, Marruecos y el propio Egipto han declinado el jugoso ofrecimiento económico.

Aparece entonces la realidad de la ciudad en todo su dramatismo: los ricos se trasladan fuera, a lugares en los cuales procuran garantizar su

${ }^{8}$ Bauman, Tiempos líquidos, 71. 
seguridad. Se procura concentrar y vigilar a los grupos "superfluos" en lugares específicos e identificables (sitios a los cuales no es raro que ni siquiera la policía tenga acceso), en tanto que se trata de mantener alejados lo más posible a aquellos que aún no han ingresado en el territorio. "A medida que se va estableciendo el multilingüismo y la diversidad cultural en el ambiente urbano propio de la era de la globalización, fenómeno que seguramente se intensificará con el tiempo, en vez de declinar, las tensiones que comporta la humillante/perturbadora/irritante extrañeza de la situación seguirá provocando, con toda probabilidad, impulsos segregacionistas."9

El tema de la ciudad se convierte así en un sitio específico en el cual se trata de encontrar una solución local a problemas que son globales. La desproporción es evidente. Los agentes globales que producen los desequilibrios económicos y los movimientos masivos de personas fracturan y vuelven muy difícil una vida humana en la ciudad. El alejamiento de los extraños, la propia reclusión en sitios cerrados y que crean una falsa impresión de seguridad, la creación de centros en los cuales los “superfluos", los "no queridos", los “descartables" son encerrados al igual que todos aquellos que inspiran desconfianza y extrañamiento, todo ello tiene efectos que se vuelven precisamente contra quienes los alimentan, quienes, en vez de crear auténticas relaciones humanas de confianza, solidaridad y seguridad, se ven cada vez más envueltos en relaciones egoístas y que conducen a una soledad llena de miedo y aprehensión. "Si se ofrece y se acepta la segregación como si fuera un remedio radical para el peligro que representan los extranjeros, la convivencia con ellos se vuelve más difícil cada día". ${ }^{10}$ No es raro que los Estados se dejen guiar por intereses egoístas que hacen imposible una vida solidaria en la que se procure un auténtico bien común. Ellos mismos suelen ser juguete de intereses globales y difíciles de regular.

En esta perspectiva resulta cada vez más difícil ver en la ciudad un centro de vida común y que ayuda a superar las propias debilidades, una unidad con límites precisos. Por el contrario, la misma ciudad sufre

${ }^{9}$ Bauman, Confianza y temor en la ciudad. Vivir con extranjeros (Barcelona: Arcadia, 2006), 32-33.

${ }^{10}$ Ibid., 38. 
este proceso de "licuefacción", pierde carácter unitario y se vuelve cada vez más porosa y fragmentada. El famoso y dramático 1\% de la población que detenta la mayor parte de la riqueza, huye de lo que considera "un peligro" ( $\mathrm{y}$, al alejarse de él, lo vuelve cada más extraño y "amenazador"), y se crean más y más "centros" en los cuales se colocan grupos humanos que "se cierran" a causa de su color, de su lengua, de sus costumbres, de su precariedad, de su carácter migratorio "irregular", por ser peticionarios de asilo o porque son refugiados, porque son pobres o simplemente porque se les considera "excedentes". La ciudad se atomiza y fragmenta de manera peligrosa. Con ello, pierde el carácter de sitio en el cual el ser humano puede realizar con los otros su propia perfección, un lugar adonde se acude para sentirse en un ambiente más humano, para gozar de aquello que es propio de la humanidad, que es la participación de los valores más auténticamente humanos.

Los medios a los cuales se está acudiendo para hacer desaparecer el miedo y la inseguridad no son aquellos que se han propuesto como falsos justificantes de la tarea del Estado, sino que este debería ser el sitio en el cual las personas y la misma sociedad alcancen su propia perfección. "El miedo y la inseguridad se van calmando gracias a la preservación de la diferencia y al hecho de poder moverse uno a sus anchas por la ciudad". ${ }^{11}$ Y es que finalmente "el sustituto de la inseguridad no es el éxtasis de la calma sino la maldición del aburrimiento". ${ }^{2}$

\section{Bernardo Secchi}

El segundo pensador en el que vale la pena detenerse es un urbanista italiano, Bernardo Secchi, quien ha dedicado al tema de la ciudad muy importantes reflexiones, ${ }^{13}$ sobre todo en su último libro, La ciudad de los ricos y la ciudad de los pobres. ${ }^{14}$

${ }^{11}$ Ibid., 57.

${ }^{12}$ Ibid., 54.

${ }^{13}$ Sobre todo Análisis de las estructuras territoriales (Barcelona: Gustavo Gili, 1968), El despilfarro inmobiliario (Barcelona: Gustavo Gili, 1977), Il raconto urbanístico (Turín: Einaudi, 1984), Prima lezione di urbanística (Roma-Bari: Laterza, 2000) y La città del ventesimo secolo (Roma-Bari: Laterza, 2013).

${ }^{14}$ Madrid: Catarata, 2015. 
Secchi, cuya obra fue publicada en 2013, en vísperas de su repentina muerte, suscitó una serie de reflexiones por haber llamado la atención a las relaciones que existen entre la ciudad y la desigualdad social. Estas últimas —observa Secchi— no han hecho sino aumentar, reflejándose naturalmente en la ciudad. ${ }^{15}$

Es importante destacar las ideas que Secchi sostiene en La ciudad de los ricos y la ciudad de los pobres. Se trata de dos tesis fundamentales:

1) En las culturas occidentales, la ciudad ha representado el sitio o el espacio donde se debe realizar el encuentro entre los seres humanos a fin de llevar a cabo su integración social y cultural. En ese espacio privilegiado siempre se han encontrado ricos y pobres, visiblemente distantes. En ocasiones, por ejemplo en algunas ciudades de la Europa medieval, la visibilidad de la diferencia se establecía por la altura de las torres donde los ricos tenían su residencia, lo que todavía se puede comprobar, por ejemplo, en la antigua ciudad italiana de Bolonia, lo que llevó en no pocas ocasiones a que se prohibiera que los ricos construyeran torres más altas que las sedes de las autoridades políticas.

Pero la época contemporánea presenta una realidad paradójica: si bien se ha logrado en general disminuir la pobreza extrema — gracias, entre otras cosas, a que fue uno de los objetivos sostenidos por la ONU hace algunos años-, se ha producido una creciente divergencia entre riqueza y pobreza, de modo que se polarizan de manera cada vez más extrema. Autores como Joseph Stiglitz, Branko Milanovic o Thomas Piketty, y en nuestro medio Miguel del Castillo y Carlos McCadden, lo han mostrado hasta la saciedad. Se revela la falsedad del argumento dado por defensores del capitalismo, según el cual "la riqueza de unos pocos beneficia a muchos". ${ }^{16}$ En un informe reciente de OXFAM, Una economía para el $99 \%$, se señala, por ejemplo, que en enero de 2017 solo ocho

${ }^{15}$ Tales reflexiones reunieron a cuatro autores, dos de ellos más cercanos a la arquitectura desde su formación de origen (Paolo Ceccarelli y Cristina Bianchetti), en tanto que los otros dos (Ada Becchi y Francesco Indovina) proceden más bien del terreno de la economía, la docencia y la investigación. El resultado se publicó con el título La ciudad del siglo XXI. Conversando con Bernardo Secchi (Madrid: Catarata, 2015). Todos ellos profundizan en los temas, los conflictos y las materias que la "nueva cuestión urbana" impone a las políticas y proyectos de la ciudad.

${ }^{16}$ Es nuevamente Zygmunt Bauman quien en obras tales como ¿La riqueza de unos pocos nos beneficia a todos? (Barcelona: Paidós, 2014), muestra la falsedad de tal posición. 
personas poseen la misma riqueza que 3600 millones de seres humanos, la mitad pobre de la humanidad, ${ }^{17}$ y que el $82 \%$ de la riqueza mundial generada el año pasado fue a parar a manos del $1 \%$ más rico. ${ }^{18}$

Todo ello hace ver, y es la primera tesis de nuestro autor, que si en Europa y en Estados Unidos, que han conocido un desarrollo intenso en los últimos siglos, desde finales del siglo XIX se han buscado mecanismos de redistribución de la riqueza, "las regiones urbanas en esta parte del planeta aparecen hoy como el lugar donde las diferencias entre ricos y pobres se vuelven dramáticamente más visibles. En el gran teatro metropolitano las injusticias sociales se manifiestan cada vez más en forma de injusticias espaciales". ${ }^{19}$

Pero las diferencias entre ricos y pobres no solo generan diferencias espaciales cada vez mayores, aunque cada una de las ciudades realiza esto de acuerdo con sus propias características, pues junto a esta realidad están también las consecuencias del cambio climático al igual que los problemas que están relacionados con una concepción de la movilidad humana como parte fundamental de los derechos básicos de las personas. A este último respecto es importante tener presente que si en 1990 el número total de migrantes internacionales era de 155 millones de personas, en 2000 se alcanzó la cifra de 177 millones y a finales de 2017 eran unos 258 millones.

Estas cifras deben verse en relación con los movimientos forzados de personas (que incluyen a los migrantes económicos, a los peticionarios de asilo, a los refugiados, a quienes son víctimas de la trata de personas, etc.), que en 2013 sumaban 51.2 millones, en 2014 eran 59.5 millones y 68.5 millones de personas a fines de $2017 .{ }^{20}$ Esto último ha originado los enormes desafíos que estos movimientos presentan para los países, en especial para Estados Unidos y para los que forman parte de la Unión Europea (en concreto Alemania, Italia, España, Polonia y Hungría,

${ }^{17}$ En esa lista se encuentra el mexicano Carlos Slim, quien controla aproximadamente el $70 \%$ del total de los servicios de telefonía móvil y el 65\% de las líneas fijas de México.

${ }^{18}$ Véase el informe en www.oxfam.org.

${ }^{19}$ Secchi, La ciudad de los ricos..., 21.

${ }^{20}$ Todas estas cifras son las proporcionadas por las Naciones Unidas. Para su mayor comprensión se puede ver Jaime Ruiz de Santiago, Movimientos migratorios y movimientos forzados de personas en el mundo contemporáneo (México: ITAM, 2019). 
para solo mencionar los más característicos). Debido a ello el Secretario General de la ONU, Antonio Guterres, afirmó:

Estas enormes cifras ocultan historias personales de sufrimiento, separaciones y pérdidas; de viajes en los que la gente se juega la vida en busca de seguridad; de luchas colosales para reconstruir vidas en circunstancias difíciles. Es desgarrador ver que se cierran fronteras, que las personas perecen en tránsito, y que tanto refugiados como migrantes son rechazados, en contravención de los derechos humanos y del derecho internacional. El costo humano es inmenso: millones de empleos perdidos, millones de niños expulsados de las escuelas, vidas atormentadas por el trauma y la intolerancia. ${ }^{21}$

Todos estos elementos hacen ver, tal es la primera tesis de Secchi, la complejidad de lo que se conoce con el nombre de la "nueva cuestión urbana": cierto que en el pasado, sobre todo en los dos últimos siglos, los cambios en el crecimiento económico y social explicaban lo espinoso de la solución de la cuestión, pero la complejidad en la que vivimos destaca la dificultad que presenta la solución de la "nueva cuestión urbana".

2) La segunda tesis subraya el hecho de que, si es cierto que la cuestión urbana vuelve al primer plano al transformarse la estructura de la economía y de la sociedad, el día de hoy tal cuestión adquiere importancia especial.

La economía se transformó con ocasión de la revolución industrial, cuando se pasó de la manufactura al sistema de fábrica; de nuevo, al organizarse el trabajo "fordista/taylorista" hizo su aparición una sociedad de masas; al hacer su aparición la "sociedad líquida" (Bauman), la "sociedad de riesgo" (Beck) o "la era del acceso" (Rifkin), también cambió la estructura espacial de la ciudad, en su manera de funcionar, en la relación entre ricos y pobres y en su imagen. Pero

hoy la nueva cuestión urbana emerge en años de profunda crisis de las economías y las sociedades occidentales, años en que la creciente individualización y desestructuración de la sociedad y un mayor conocimiento de la escasez de recursos ambientales, unida a demandas crecientes

${ }^{21}$ Las cifras aparecen en Ibid., 14-16. 
en lo relacionado con la seguridad, la salud y la educación, el progreso tecnológico y el cambio de las reglas de interacción social, construyen imágenes, escenarios, políticas y proyectos que son en parte contradictorios entre sí. ${ }^{22}$

Como se ha visto, en todas las sociedades se han dado estrategias de exclusión de ciertos grupos sociales, en especial de las clases menos favorecidas desde el punto de vista económico, lo que siempre conduce al rompimiento de la solidaridad, al distanciamiento de actividades, edificios y espacios públicos. Esto adquiere rasgos dramáticos en nuestra época. Objetos y espacios adquieren una función simbólica: altura y localización de los edificios, construcción de bardas, etc., todo refleja las estructuras económicas y sociales. Y aunque las tradiciones de los países y sus respectivas posiciones han dado lugar a muy diferentes estructuras urbanas, "quizá, bajo el impulso de la globalización y de los imponentes movimientos de población entre varios continentes que caracterizan el último siglo y medio, tenderán cada vez más a asemejarse y a unificarse, como han tendido a parecerse las políticas redistributivas del welfare desde su comienzo, al final del siglo XIX, hasta los últimos decenios del veinte". ${ }^{23}$ Y aunque la ciudad europea aparece hasta ahora como diferente de las de otros continentes, son muchos los indicadores que apuntan a que "las tradiciones más recientes pueden arrollar a las más antiguas", ${ }^{24} \mathrm{y}$ causar diversos problemas para el futuro de la ciudad al igual que para las políticas que procurarán crearlo.

Secchi observa que fue en Inglaterra, a finales del siglo XVIII, donde comenzaron a modificarse los patrones del hábitat y la ciudad. Por diversos factores se privilegió el mundo de la casa y de la familia, alejándose el sitio de los negocios y del trabajo. Hacia mediados del siglo XIX, la burguesía y la mayor parte de la clase media cultivaron los valores de la privacidad, la comodidad y el decoro. Se prestó más atención a la limpieza y el cuidado del cuerpo y la burguesía se definió como clase. Un siglo más tarde, en la medida en que el grupo económicamente privilegiado se hizo

${ }^{22}$ Secchi, La ciudad de los ricos ..., 24.

${ }^{23}$ Ibid., 42.

${ }^{24}$ Ibid., 43. 
más pequeño y los pobres aumentaron, se establecieron políticas más claras de identificación y reconocimiento, acompañadas de otras de separación y exclusión. Los barrios ricos de las ciudades europeas se separaron y distinguieron de los pobres y menesterosos.

A finales del siglo XX apareció el llamado "urbanismo del movimiento moderno", que se centró en los valores de seguridad y de calidad ambiental, lo que condujo tanto en Canadá y Estados Unidos como en América Latina, a la construcción de condominios fechados ${ }^{25}$ o gated communities, integrados por varios cientos o miles de personas, por lo general "de elevado nivel económico y/o cultural, y/o social; de rentas elevadas, y/o de elevado nivel de educación y profesionalidad, y/o de una red de relaciones sociales con los más altos grados del poder", ${ }^{26}$ Al respecto, el juicio de Bernardo Secchi, que coincide con el de Bauman, es tajante y claro: "la gated community es la negación de la ciudad". ${ }^{27}$ Construir comunidades cerradas, alejadas, a las que pocos tienen acceso y que se llenan de sistemas de seguridad, revelan un hosco alejamiento de los otros, un rechazo de los demás, que son vistos con desconfianza y desdén. "Los otros" son los que hay que evitar, sobre todo si son pobres y representan a "los descartables", a "los superfluos" y son fuente - eso es lo que los ricos piensan- de todos los males que aquejan a la sociedad.

De este modo se distinguen y fragmentan distintos territorios en la ciudad. A esto se añade que, desde la década de 1970, aumentan los flujos migratorios y los distintos grupos, unos ricos y la mayor parte pobres, se van separando según sus tradiciones y con ello incrementan el rompimiento de la unidad y de la solidaridad. ${ }^{28}$ La ciudad se vuelve

${ }^{25}$ En español, condominios cerrados. Se refiere a las urbanizaciones rodeadas de fuertes sistemas de seguridad, que impiden entrar a los extraños, que procuran brindar los servicios propios de la ciudad y que están hechos para dar a sus moradores la impresión de armonía y paz.

${ }^{26}$ Secchi, La ciudad de los ricos ..., 49.

${ }^{27}$ Ibid., 50.

${ }^{28}$ Paolo Ceccarelli, al comentar la obra de Secchi, habla de una "máquina de la segregación" que se manifiesta en el mundo de diversas maneras: "Campos de refugiados, campos de evacuados, campos de emigrantes, campos de extranjeros, zonas para personas en espera, zonas de tránsito, centros de retención o de detención administrativa, centros de identificación y de expulsión, puntos de paso fronterizo, centros de acogida de solicitudes de asilo, centros de acogida temporal, barrios de refugiados, barrios de inserción de emigrantes, 'guetos', 'junglas', hogares, casas de emigrantes [...]: la lista de estas definiciones, ya habituales, se alarga cada vez más". Ceccarelli, La ciudad del siglo XXI... 
difusa, se atomiza, y no es raro que se deje el centro a los grupos migratorios que se convierten en estigmas de zonas concretas de la ciudad. Se rompe la unidad y aumenta la dispersión, que se fija en el centro o en los suburbios de la ciudad. "El suburbio se ha convertido en una institución dominada por la idea de la distinción: de la riqueza, la raza y la etnia." ${ }^{29}$ Las formas y los límites de las ciudades se disuelven y aparecen múltiples enclaves o grupos que difícilmente llegan a realizar la unidad. Con frecuencia, los que fueron sitios de trabajo densamente poblados son abandonados y comienzan a concentrarse el desempleo y la pobreza. Así se explica que, sobre todo a partir de la segunda mitad del siglo XX, se vuelva obsesiva la inquietud por encontrar respuesta al problema de la vivienda, sin tomar en consideración los intereses colectivos y los espacios públicos. No hay una preocupación por reflejar en los espacios los valores de una sociedad más democrática, de una política que busque la integración de los diferentes grupos sociales, para lograr la unidad de las culturas y prácticas del espacio.

Como en Estados Unidos las desigualdades sociales son más acentuadas, ${ }^{30}$ estas características se vuelven más claras en tanto que el urbanismo europeo ha hecho esfuerzos por reducir las desigualdades sociales gracias a la prestación de servicios básicos para todos sin distinción. Uno puede añadir que México se aleja cada vez más de los patrones europeos y, por desgracia, el urbanismo establece las diferencias de clases cada vez con mayor claridad. "En un periodo de intensos movimientos de población a escala planetaria, el mundo y la ciudad se muestran ahora habitados por sujetos irreductiblemente diferentes y las desigualdades han demostrado ser también el resultado de los persistentes conflictos entre distintos." $" 31$

La tesis central de Secchi es que si la historia de la ciudad muestra que ha sido una máquina de exclusión social, también lo puede y lo debe ser de integración y unidad. Cierto que la tarea de planificar y diseñar la

${ }^{29}$ Secchi, La ciudad de los ricos..., 59.

${ }^{30}$ Es interesante recordar que, de acuerdo con el World Prison Brief, editado por el Instituto de Investigación en Políticas para Delitos de la Universidad de Londres, Estados Unidos, cuyo sistema carcelario se ha privatizado en los últimos años, posee la población carcelaria más grande del mundo: 2.2 millones de personas, de un total mundial de 11 millones.

${ }^{31}$ Secchi, La ciudad de los ricos..., 69. 
ciudad se ha vuelto inmensamente difícil; sin embargo, es esencial recuperar la participación de los individuos, articular el imaginario urbano e intensificar los valores democráticos, a fin de superar la desconfianza y el conflicto existente. Resulta fundamental cambiar los comportamientos individuales y colectivos en la sociedad, la economía y las instituciones occidentales, a fin de lograr que el urbanismo ayude a crear una ciudad profundamente humana, en la que reinen no los valores de la ganancia individual y el egoísmo, sino los de la solidaridad y atención a lo colectivo, que los rasgos y valores individuales sean respetados y protegidos en la conformación de valores auténticamente comunes.

De este modo, los primeros años del siglo XXI en que vivimos permiten que se revele de manera clara la importancia de la cuestión urbana, que posee un carácter multidimensional. Asistimos "a una extraordinaria redistribución espacial de la producción y la creación de riqueza, que es acompañada por una igualmente extraordinaria redistribución de la población entre las diferentes partes del planeta, entre los diversos Estados y dentro de los propios países". ${ }^{32}$ Y si es cierto que en las últimas décadas del siglo XX la ciudad se convirtió en una poderosa máquina de suspensión de derechos de los individuos y de la colectividad, esto no se ha hecho sin "una ideología y una retórica: la ideología del mercado y la retórica de la seguridad". ${ }^{33}$

Son puntos fundamentales los que hay que cambiar, pues - dice nuestro autor- es necesario alcanzar formas nuevas de empleo pleno y de estructurar una relación diferente entre el trabajo y la sociedad; es fundamental establecer sistemas adecuados de transporte colectivo y construir espacios verdaderamente colectivos, en los cuales los seres humanos se puedan encontrar y gozar su humanidad. Ello no requiere obras grandes y espectaculares, sino que se deben adoptar políticas que garanticen en la ciudad permeabilidad y accesibilidad a la naturaleza y a las personas: a todas, sin distinción. "Será necesario desarrollar más la democracia, reduciendo las desigualdades en el espacio". ${ }^{34}$

${ }^{32} \mathrm{Ibid}$., 85.

${ }^{33}$ Ibid., 86.

${ }^{34}$ Ibid., 90. 
Es de este modo que Bernardo Secchi sostiene la tesis fundamental de su obra, la que es declarada desde el principio: "El urbanismo tiene importantes y precisas responsabilidades en el empeoramiento de la desigualdad y el proyecto de la ciudad debe ser uno de los puntos de partida de cualquier política dirigida a su eliminación u oposición". 35

\section{Jan Gehl}

Llegamos al tercer pensador en el que interesa detenernos. Se trata de Jan Gehl, danés de muy reconocido prestigio y que ha inspirado una novedosa concepción de la ciudad, que rompe con numerosos esquemas del pasado y que ha sido acogida en ciudades tales como Copenhague, Londres, Nueva York, Bogotá, Moscú, San Francisco, Shanghái y varias urbes australianas (Melbourne, Perth, Adelaida, Sídney, Auckland, Wellington, Christchurch, Launcertin, Hobart), y que el día de hoy anima la remodelación que conoce Madrid. ${ }^{36}$

Tras haber visto la ciudad como un sitio donde se refleja la desigualdad económica y social, tanto desde el punto de vista sociológico (Bauman) como urbanístico (Secchi), con Gehl se pasa a un planteamiento práctico, que trata de realizarse en la planeación urbanística de numerosas ciudades y de superar una visión funcionalista, en la cual se han privilegiado las tareas o funciones de la ciudad, lo que ha llevado a dar inmensos espacios a los edificios y a los automóviles, para tratar de devolverle su dimensión humana. Es la persona humana que se afirma en espacios democráticos, en espacios públicos que sirven para la interacción humana y que reafirma el derecho a la ciudad. En esta visión, lo que hace "buena" a una ciudad es la gente y no los edificios ni mucho menos los automóviles. Por ello lo que pretende el planteamiento urbanístico de Gehl

${ }^{35} \mathrm{Ibid} ., 15$.

${ }^{36}$ Es interesante observar que, si en el centro de esta ciudad se trata de crear espacios más humanos y participativos, los planes para el "Madrid Norte" responden a los deseos de resolver el "problema de la vivienda" atendiendo a la pura funcionalidad y sin ocuparse de los reales problemas colectivos de humanización y convivialidad. Todo ello es objeto de una acalorada polémica social. 
es hacer visible a la gente, interactuando en espacios públicos y usando de la ciudad como sitio de encuentro y de realización humana. ${ }^{37}$

Jan Gehl afirma con fuerza que la ciudad en el pasado había sido planeada para que en ella el ser humano pudiese vivir y desarrollarse humanamente, privilegiando los espacios públicos, como mercados, plazas, jardines, lugares de encuentro y de realización de actividades sociales (representaciones, juegos, manifestaciones y otras). Se afirmaba la primacía de la vida sobre la función. Esto tuvo un paréntesis cuando, con el modernismo urbanístico de la década de 1960, se privilegió la función de los edificios públicos, su forma espacial, y se olvidó a las personas concretas, se dijo adiós a la escala humana y se favoreció la presencia y el desarrollo de los automóviles. Gehl observa atinadamente que "el modernismo [urbanístico] ha durado unos sesenta o setenta años, precisamente el lapso en el que se olvidó la dimensión humana". ${ }^{38}$

Además, se debe observar que "en todos los casos, los esfuerzos por aliviar la presión del tráfico automovilístico construyendo más vialidades y espacios de estacionamiento ha generado más tráfico y más congestión de autos". ${ }^{39}$ En este contexto no es de extrañar la reciente decisión de diversos cantones suizos de impedir la construcción de nuevas carreteras, porque quitan belleza al paisaje y olvidan la dimensión humana.

Gehl cita como ejemplos de buen desarrollo humano y de un "buen vivir" a Venecia y a Siena, donde el humano se encuentra a gusto. Son ciudades bellas y funcionales por tener una dimensión verdaderamente humana y porque las diferentes tareas del ser humano - casa, diversión, trabajo, encuentro con los otros- hallan feliz realización. Por el contrario, un ejemplo de un urbanismo funcional, donde "se ha dicho adiós a la preocupación por la gente", la cual ha sido sacrificada a la función arquitectónica, es Brasilia. Precisamente al síndrome de Brasilia el autor dedica toda una sección de su obra Cities for people a fin de mostrar las características y consecuencias de este tipo de planeación

${ }^{37} \mathrm{El}$ antecedente más importante de este movimiento urbanístico se encuentra en la obra de Jane Jacobs, The death and life of great American cities (1961).

${ }^{38}$ Jan Gehl, Cities for people (Washington: Island Press, 2010). Edición para Kindle.

${ }^{39}$ Ibid. 
urbanística que genera ciudades "claras" por la distribución de sus edificios, planeadas "desde arriba", que poseen formas y estructuras visibles (Brasilia, se dice repetidamente, posee la forma de un avión o de una paloma, en cuyo cuerpo central se encuentran los edificios gubernamentales, en tanto que las casas se localizan en "supercuadras" a lo largo de las alas), que despierta interés en el visitante pero que desagrada enormemente a quien ahí vive. No se tuvo presente la dimensión humana.

Gehl afirma que precisamente:

la dimensión humana en las ciudades ha sido olvidada durante años, y muchas veces la consecuencia es que se da la prioridad al tránsito de automóviles. Poco a poco, casi todas las ciudades han establecido oficinas o departamentos de tráfico, que calculan el flujo de vehículos y determinan las condiciones de los estacionamientos año tras año. Recogen información y detectan tendencias, realizan modelos de tráfico y del impacto de estos análisis, y en este proceso los automóviles son cada vez más visibles y omnipresentes en la planeación urbana. ${ }^{40}$

El esfuerzo realizado por Gehl consiste precisamente en hacer efectivo el derecho a la ciudad, que haga realidad ciudades vivibles, seguras, sustentables y saludables. Para ello, se debe tener presente, como lo señaló recientemente Gehl en el Colegio de Arquitectos de Madrid, que "cada vez que pones un ladrillo en cualquier parte, manipulas la calidad de vida de las personas [...] Si solo haces forma, es escultura. Pero se convierte en arquitectura si la interacción entre la forma y la vida es exitosa". ${ }^{41}$ Y es que si "nosotros primeramente damos forma a las ciudades, son ellas las que posteriormente nos dan forma a nosotros". ${ }^{42}$

En su obra citada, Gehl establece con detenimiento las relaciones que existen entre los sentidos humanos y las proporciones arquitectónicas, pues estas relaciones son determinantes para la comunicación humana

${ }^{40}$ Ibid.

${ }^{41}$ Jan Gehl, "Pensar en urbano: ciudades para la gente" (conferencia, Colegio Oficial de Arquitectos de Madrid, 29 de junio de 2017), https://www.coam.org/es/canal-coam/videos/jornadas-y-actos-2016/pensar-urbano-ciudades-gente-jan-gehl.

${ }^{42}$ Ibid. 
y la interacción. En el capítulo "La ciudad vivible, segura, sostenible y saludable" se determina con mayor precisión cómo "la ciudad para la gente" asegura estos elementos. Ahí se asienta que estos cuatro objetivos "pueden ser reforzados de manera inconmensurable al aumentar la preocupación por los peatones, por los ciclistas y por la vida de la ciudad en general". ${ }^{43}$ Una ciudad es vivible, señala, cuando las personas son invitadas a caminar, a usar la bicicleta y a permanecer en los espacios públicos. A su vez, los adecuados espacios públicos requieren un buen sistema de transporte colectivo: se trata de dos caras de la misma moneda.

Si son las personas y no los automóviles las invitadas a la ciudad, el movimiento de los peatones y la vida de la ciudad aumentarán en las mismas proporciones. Y del mismo modo que se debe lograr que las ciudades inviten a una vida ciudadana, "hay muchos ejemplos de cómo la renovación de un pequeño espacio e incluso el cambio de un mueble o de ciertos detalles invitan a las personas a un cambio total de actitudes". ${ }^{44}$

De este modo, el urbanismo debe ser un esfuerzo por crear espacios y sitios auténticamente humanos, que realicen el ideal democrático invitando a la presencia y a la participación, donde la comunicación y la convivencia se hagan realidad, donde la solidaridad sea el ambiente de vida y desarrollo.

En nuestros días, muchas ciudades van conformándose a las ideas propuestas por Jan Gehl, y permiten una experiencia totalizadora $\mathrm{u}$ holística por hacer participar al conjunto de las facultades humanas y por tomar en cuenta las exigencias del vivir humano en sociedad, que comprende igualmente elementos ambientales y de inclusión social. Estas ciudades hacen ver su bondad o calidad porque en ellas el ser humano se detiene y se siente a gusto, porque en ellas lo experimentado, en el sentido totalizador del término, agrada. Tomás de Aquino definía la belleza precisamente como "aquello que agrada a la vista", al igual que Jan Gehl afirma que una buena ciudad proporciona el mismo efecto que una buena fiesta, es decir, que nos gusta estar ahí y nos complacemos: no queremos irnos.

${ }^{43}$ Ibid.

${ }^{44}$ Ibid. 
Se pueden terminar estas reflexiones preguntándonos cuáles de los cánones presentados por estos autores son los que guiarán la construcción de megaciudades, como la de Jing-Jun-Ji, en China, que deberá albergar a 130 millones de personas, o el diseño de espacios reducidos como el que se prepara para ampliar el ITAM. Pueden ser sitios que evidencien y refuercen la desigualdad, sitios que inviten a la exclusión o a la inclusión, a la comunidad o a la dispersión, lugares espectaculares por sus dimensiones desproporcionadas o por sus proporciones humanas, esfuerzos de diseño para realizar espacios fríos y poco acogedores o espacios que inviten a quedarse y disfrutar de su calidez humana. 